\title{
Thermal-Mechanical Optimization of Folded Core Sandwich Panels for Thermal Protection Systems of Space Vehicles
}

\author{
Chen Zhou, ${ }^{1,2}$ Zhijin Wang, $^{1}$ and Paul M. Weaver ${ }^{2,3}$ \\ ${ }^{1}$ Minister Key Discipline Laboratory of Advanced Design Technology of Aircraft, Nanjing University of Aeronautics and Astronautics, \\ Nanjing 210016, China \\ ${ }^{2}$ Advanced Composites Centre for Innovative and Science, University of Bristol, Queen's Building, University Walk, \\ Bristol BS8 1TR, UK \\ ${ }^{3}$ Bernal Institute, University of Limerick, Limerick, Ireland \\ Correspondence should be addressed to Zhijin Wang; zhijin@nuaa.edu.cn
}

Received 16 February 2017; Accepted 18 July 2017; Published 20 December 2017

Academic Editor: Hikmat Asadov

Copyright (C) 2017 Chen Zhou et al. This is an open access article distributed under the Creative Commons Attribution License, which permits unrestricted use, distribution, and reproduction in any medium, provided the original work is properly cited.

\begin{abstract}
The integrated thermal protection system (ITPS) is a complicated system that addresses both mechanical and thermal considerations. An M-pattern folded core sandwich panel packed with low-density insulation material provides inherently low mass for a potential ITPS panel. Herein, we identify the most influential geometric parameters and establish a viable, computationally efficient optimization procedure. Variables considered for optimization are geometric dimensions of the ITPS, while temperature and deflection are taken as constraints. A one-dimensional (1D) thermal model based on a modified form of the rule of mixtures was established, while a three-dimensional (3D) model was adopted for linear static analyses. Parametric models were generated to facilitate a design of experiment (DOE) study, and approximate models using radial basis functions were obtained to carry out the optimization process. Sensitivity studies were first conducted to investigate the effect of geometric parameters on the ITPS responses. Then optimizations were performed for both thermal and thermal-mechanical constraints. The results show that the simplified 1D thermal model is able to predict temperature through the ITPS thickness satisfactorily. The combined optimization strategy evidently improves the computational efficiency of the design process showing it can be used for initial design of folded core ITPS.
\end{abstract}

\section{Introduction}

Space vehicles encounter severe aerodynamic heating and pressure loads during ascent and reentry. Thermal protection systems (TPS) are therefore required to maintain the underlying structural temperature within acceptable limits [1]. Conventional TPS are not load-bearing components, while an integrated thermal protection system (ITPS) is capable of bearing both mechanical and thermal loads $[2,3]$. Both metal foam core and corrugated core have been widely investigated to achieve this goal [3-9]. Metal foam is an attractive proposition as a sandwich core for its desirable combination of mechanical, thermal, acoustic, and impactabsorbing properties [10]. Venkataraman et al. [4] optimized the density distribution to minimize the heat conduction through the metal foam thickness. Zhu et al. [5] evaluated the performance of the metal foam-based ITPS and compared it with the conventional TPS design. Furthermore, an open-cell metal foam core also allows for active cooling of the sandwich structure. Rakow and Waas [2] studied the thermal-mechanical response of actively cooled metal foam sandwich panels for a thermal protection system. It was shown that both temperature and thermal-mechanical deformation were reduced via active cooling. Corrugated core sandwich structures have been proposed for ITPS due to the favourable strength-to-weight ratio and good manufacturability. Bapanapalli et al. [3] studied the corrugated core sandwich panel concept and established an optimization procedure to minimize the weight of the ITPS panel. Sharma et al. [6] homogenized the ITPS panel based on finite element models and constructed multifidelity models to reduce the cost during optimization for a given accuracy. Xie et al. [7, 11] 
developed a two-step optimization approach to obtain the optimal ITPS dimensions.

Another promising structure suitable for the ITPS concept is a folded core sandwich panel using a threedimensional core which can be folded from a planar base material along certain geometric lines $[12,13]$. It can be made from various sheet materials in a convenient continuous process and can be tailored into different geometries meeting different functional requirements. Besides, the open-cell design of folded core eliminates corrosion issues which is a common problem for metallic honeycomb core structures, especially for those used in the aerospace industry [14].

These advantages have led to several research programmes into folded core structure [15-20]. Wang and Xu [15] experimentally investigated the soundproof characteristics of folded core sandwich plates. Heimbs et al. [16, 17] evaluated the mechanical behaviour of folded structures under compression, shear, and impact loads both experimentally and numerically in a series of studies. Sab and Lebée [18, 19] estimated the bounds for the transverse shear modulus of a folded core by using a unit load method, and later BendingGradient plate theory was applied to assess its shear stiffness. Currently, however, most research on folded core structures focuses on its acoustic, mechanical, and impact properties, while little work exists on its capacity for potential thermal protection.

The present study establishes a thermal-mechanical optimization procedure for a folded core sandwich-based ITPS. First, a novel analytical formulation for the effective thermal conductivity is established using a modified rule of mixtures approach, and a comparative study between the homogenized one-dimensional (1-D) and corresponding three-dimensional (3-D) thermal models was performed. Then the simplified $1 \mathrm{D}$ thermal model is used to determine the temperature distribution, which is taken as the thermal load in the subsequent linear static analyses of the folded core sandwich panel. Sensitivity studies are then conducted to identify the most influential parameters. Finally, the optimization approach is presented and used to obtain the optimal results of the ITPS.

\section{Folded Core TPS}

2.1. Geometric Description. The integrated thermal protection system (ITPS) is a sandwich panel with two thin face sheets separated by folded cores, which can be made of homogeneous, isotropic materials such as metals or orthotropic materials such as composite laminates, as shown in Figure 1. The empty space in the folded core is packed with a non-loadbearing insulation material such as SAFFIL [3]. As a single component, this multifunctional structure provides thermal protection as well as load-bearing capabilities.

Typically, a unit cell of M-pattern folded core can be completely described by a set of five independent geometric parameters as shown in Figure 17(a). Using terms in [21], the geometric model is defined by the folded core height $H$, half of the zigzag lines pitch $S$, the saw-tooth lines pitch $2 L$, the zigzag lines amplitude $V$, and spacing between the saw-tooth lines $B$.

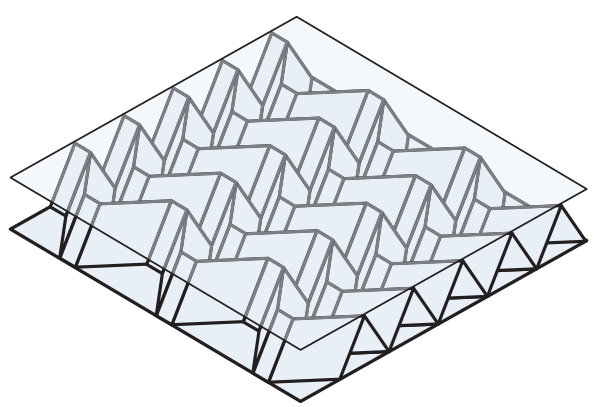

FIGURE 1: Illustration of folded core sandwich structures.

2.2. Material Properties. Material selection for different parts of the sandwich panel is based upon previous experience with ARMOR TPS [22] and the corrugated core ITPS [3]. Inconel 718, Ti-6Al-4V titanium alloy, and aluminium 2024 alloy are used for the top-face sheet, folded core, and the bottom-face sheet respectively. SAFFIL foam with a density of $48 \mathrm{~kg} / \mathrm{m}^{3}$ is used for insulation.

Temperature dependent thermal properties are used in our heat transfer analyses [23, 24], while physical properties are considered constant [7] in linear static and buckling analyses to further simplify the model in this preliminary study. The heat transfer mechanisms through the fibrous insulation involve solid conduction, gas conduction, radiation, and possible natural convection. For simplicity, effective thermal conductivity is used to estimate the combined heat transfer mechanisms in the SAFFIL insulation [25]. All used material properties are found in [23-25].

\section{Heat Transfer Analysis}

3.1. Thermal Load and Boundary Conditions. Incident heat flux on the vehicle varies with many factors, such as the shape of the vehicle, the trajectory profiles, and different locations on the vehicle. For the current study, incident heat flux during reentry of a reusable launch vehicle (RLV) is used [3]. The outer surface of the top-face sheet is subjected to a transient heat flux as shown in Figure 2. The inner surface of the bottom-face sheet is conservatively assumed to be adiabatic. The initial structural temperature is assumed to be $295 \mathrm{~K}$.

Radiation to the ambient atmosphere is also considered with a constant emissivity of 0.86 , which is typical for TPS exterior material and surface treatments. Convection is modelled after the vehicle touches down on the ground. The convective heat transfer coefficient $h$ is assumed to be $6.5 \mathrm{~W} / \mathrm{m}^{2} \cdot \mathrm{K}[3]$, and the ambient temperature is assumed to be $295 \mathrm{~K}$.

3.2. Simplified 1D Thermal Model. In order to study the structural performance under temperature environments, it is necessary to obtain the temperature distribution through the panel. Miller and Weaver [26, 27] developed analytical models based on techniques of integral transforms and separation of variables and described the transient temperature distribution through an air-filled box structure and a multilayered plate, respectively. Finite element method 


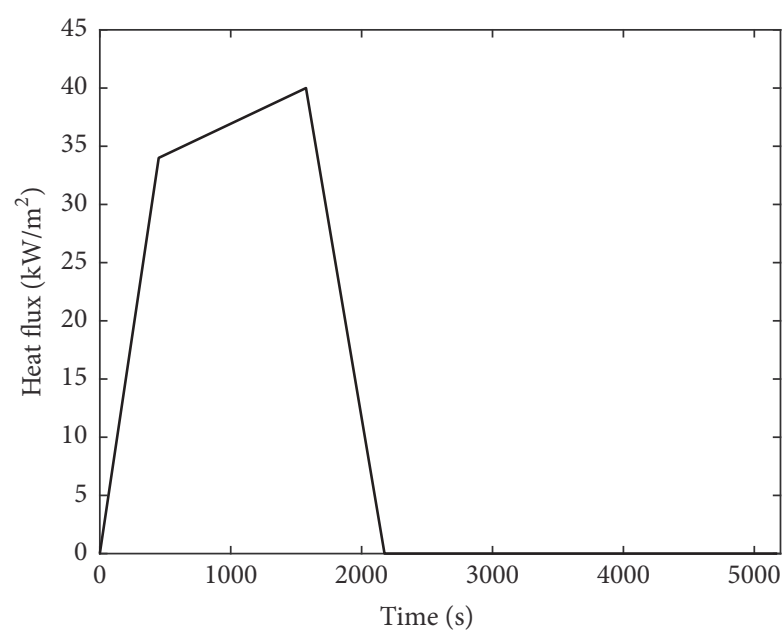

Figure 2: Heat flux profile.

(FEM) models were also established for comparison purposes and showed a good fit. In this preliminary study, FEM models are currently adopted using Abaqus [28] to determine the temperature distribution. Due to the periodic characteristic of folded core, it is assumed that there is no lateral heat flow out of the unit cell, which means the heat flux incident on a unit cell only affects this specific unit cell. Although the temperature distribution could possibly be marginally different in a real ITPS panel due to the fact that the ITPS panel is mounted on the stringers and frames which could cause potential lateral heat flow across units, this secondary effect is not taken into consideration in this preliminary design. According to studies by Blosser et al., 1D models can reasonably predict temperatures in TPS systems [25, 29]. In order to reduce the time cost of the transient heat transfer analyses, the folded core ITPS thermal model is further simplified to a $1 \mathrm{D}$ model.

In the following the homogenized properties of the folded core are calculated using a modified rule of mixtures approach. The homogenized results for density $\rho$, specific heat $c$, and thermal conductivity $k$ are

$$
\begin{aligned}
\rho_{e}= & \rho_{w} \cdot V_{w}+\rho_{s} \cdot V_{s}, \\
c_{e}= & \frac{1}{\rho_{e}}\left(c_{w} \cdot \rho_{w} \cdot V_{w}+c_{s} \cdot \rho_{s} \cdot V_{s}\right), \\
k_{e}= & {\left[k_{w} \cdot\left(V_{w}{ }^{S} \cdot \sin ^{2} \theta \cdot \sin \varphi\right)+k_{s} \cdot V_{s}^{S}\right] \cdot V^{S} } \\
& +\left[k_{w} \cdot\left(V_{w}{ }^{B} \cdot \sin ^{2} \gamma\right)+k_{s} \cdot V_{s}^{B}\right] \cdot V^{B},
\end{aligned}
$$

where $V$ is the volume fraction; the subscripts $w, s$, and $e$ refer to web, SAFFIL, and homogenized core, respectively; the superscripts $S$ and $B$ represent the parallelepiped part and cuboid part of the core along the $Z$ direction (see Figures 17(a) and 18). Specifically, (3) shows that thermal conductivity is enhanced by considering the irregular shape of the core. The terms $\theta$ and $\gamma$ are inclined angles and $\varphi$ is the included angle, as shown in Figure 18. The detailed derivation of the homogenized properties is given in the appendix.

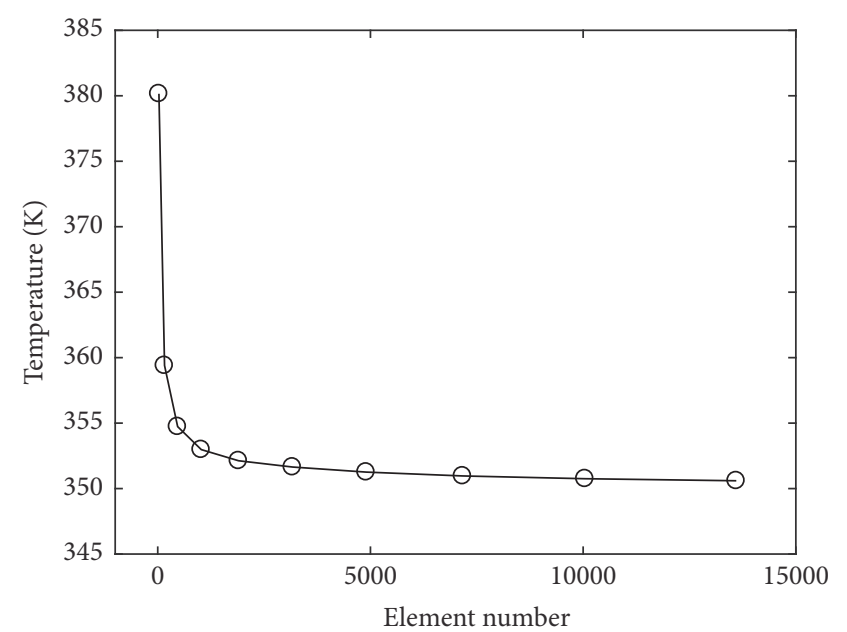

FIgURE 3: Convergence results for temperature at the middle of bottom-face sheet.

In the case of transient heat transfer analyses, we compare results from the $3 \mathrm{D}$ and $1 \mathrm{D}$ thermal models. The 8 -node brick element (DC3D8) and 2-node link element (DC1D2) were used for the $3 \mathrm{D}$ and $1 \mathrm{D}$ models, respectively. Mesh convergence studies (Figure 3 ) for the 3D model show how temperature changes with the number of elements at the midpoint of the bottom-face sheet.

The mesh size with 6195 nodes and 4900 elements was eventually settled upon for the $3 \mathrm{D}$ heat transfer model as its temperature results differed only marginally from a finer mesh. Similar studies were also carried out for the 1D model, resulting in 21 nodes and 20 linear link elements of type DC1D2 being used. Figure 4 shows the mesh for the 3D and $1 \mathrm{D}$ heat transfer models separately, where Figure 4(a) is the mesh with SAFFIL, while Figure 4(b) refers to the solid portion only, that is, face sheets and web. A single run for each model shows that the $1 \mathrm{D}$ model reduces the computational time by nearly 70 percent. Several key locations on the folded core panel are monitored through analyses and are schematically illustrated in Figure 5.

The transient thermal analyses results for a folded core sandwich panel are shown in Figures 6-8, where temperatures versus reentry times at three positions (top, mid, and bottom) are illustrated. Figure 6 shows that on the topface sheet the 1D model can predict temperature accurately, which is approximately the average value of the four locations' temperatures in the 3D model. Figure 7 shows that the $1 \mathrm{D}$ temperatures are only slightly higher than the $3 \mathrm{D}$ model results on the bottom-face sheet, thus showing good validation of the simpler 1D model. Figure 8 shows the temperature variation with time at the mid position of the core. The maximum deviation between the $1 \mathrm{D}$ and $3 \mathrm{D}$ models occurs when the heat flux is relatively high. This phenomenon is expected to occur due to the existence of the inclined angles. As the $1 \mathrm{D}$ prediction lies mostly in the middle of the $3 \mathrm{D}$ results and because it reflects the changing tendency of the temperature correctly, it is considered acceptable for use in the preliminary design process. Based upon previous analyses, it can be concluded that the 1D heat transfer model 


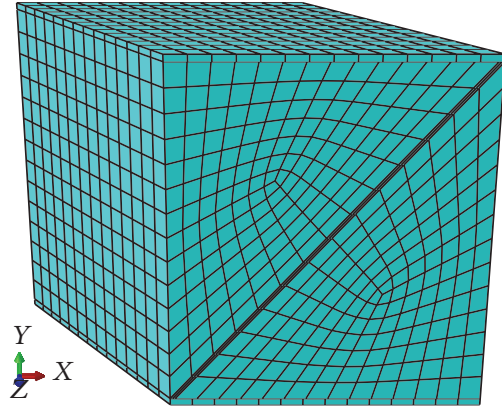

(a)

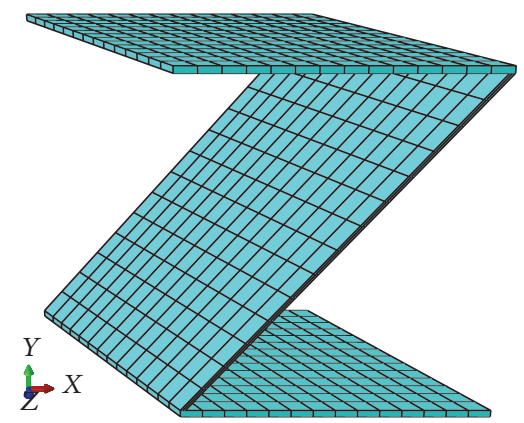

(b)

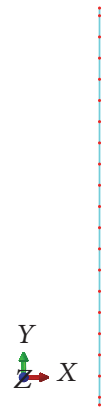

(c)

FIgUre 4: Mesh for (a) 3D with SAFFIL, (b) 3D without SAFFIL, and (c) 1D thermal model.

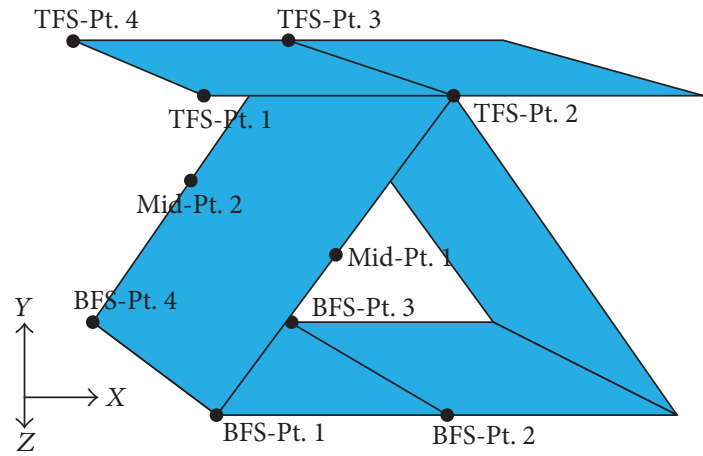

FIGURE 5: Points (Pt.) investigated on the panel.

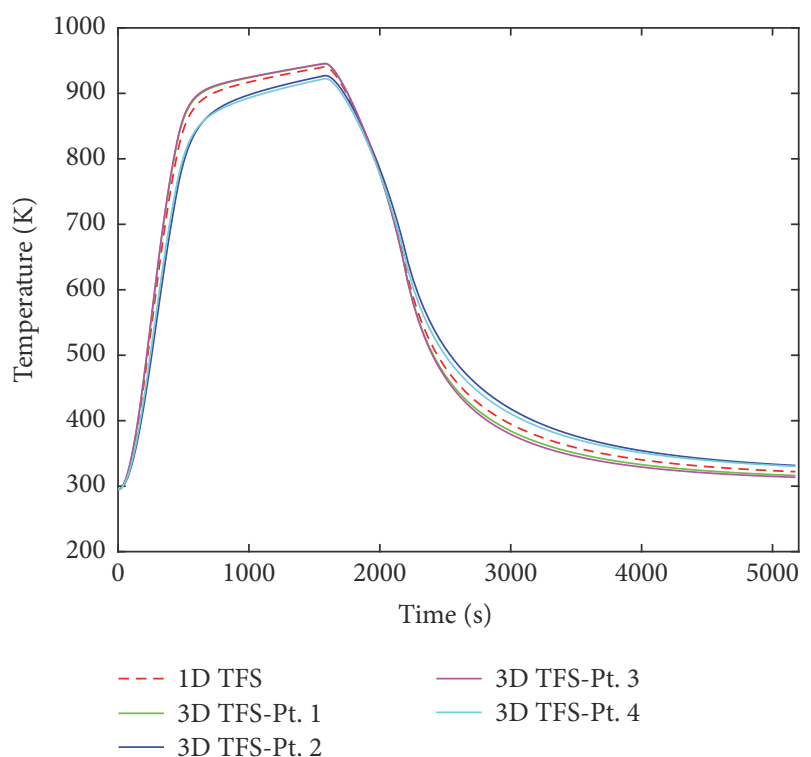

FIGURE 6: Temperature variations at top-face sheet (TFS) for the 1D and $3 \mathrm{D}$ folded core thermal models.

predicts temperature with satisfactory accuracy through the ITPS thickness.

During the transient heat transfer analysis, the maximum temperature of the bottom-face sheet is obtained. At the same time, the temperature distribution through the panel

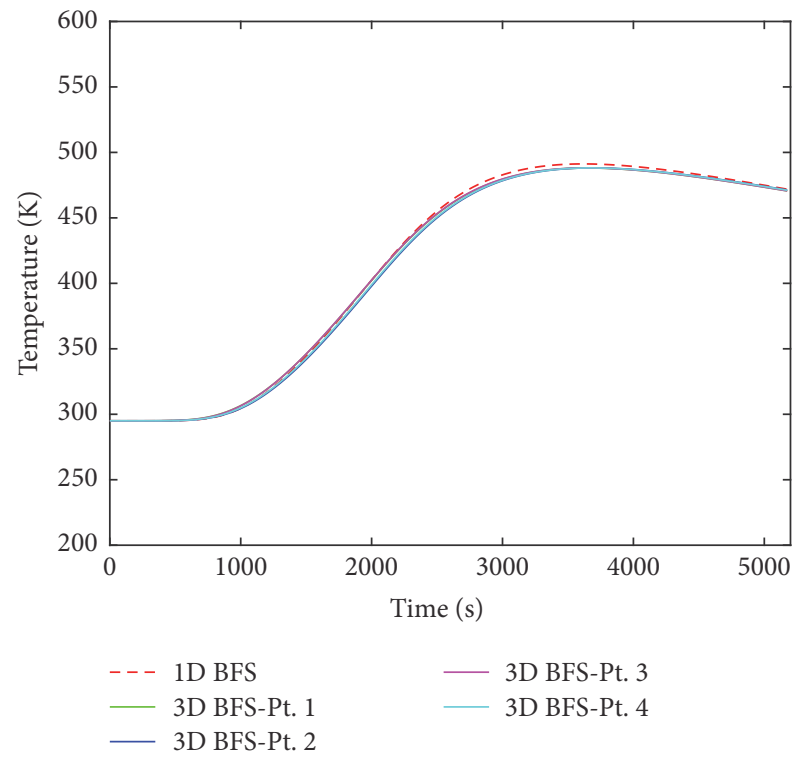

FIGURE 7: Temperature variations at bottom-face sheet (BFS) for the $1 \mathrm{D}$ and $3 \mathrm{D}$ folded core thermal models.

thickness is also extracted for subsequent use in the linear static analyses described in the next section, achieved by using python code from the FEM results file.

\section{Linear Static Analyses}

In this section, the 3D model used for the linear static analysis is described. As the mechanical properties of the SAFFIL material are negligible when compared to the face sheets and the web, the soft insulation material is not taken into account during structural analyses. In this current study, four unit cells were considered in the folded core panel. To decrease the computational expense, only half of the panel was modelled in the FE linear static analysis. The $3 \mathrm{D}$ folded core panel is modelled using the eight-node shell element (S8R). Mesh convergence studies were conducted, with approximately 9715 nodes and 3110 elements used in the linear static model as shown in Figure 9. 


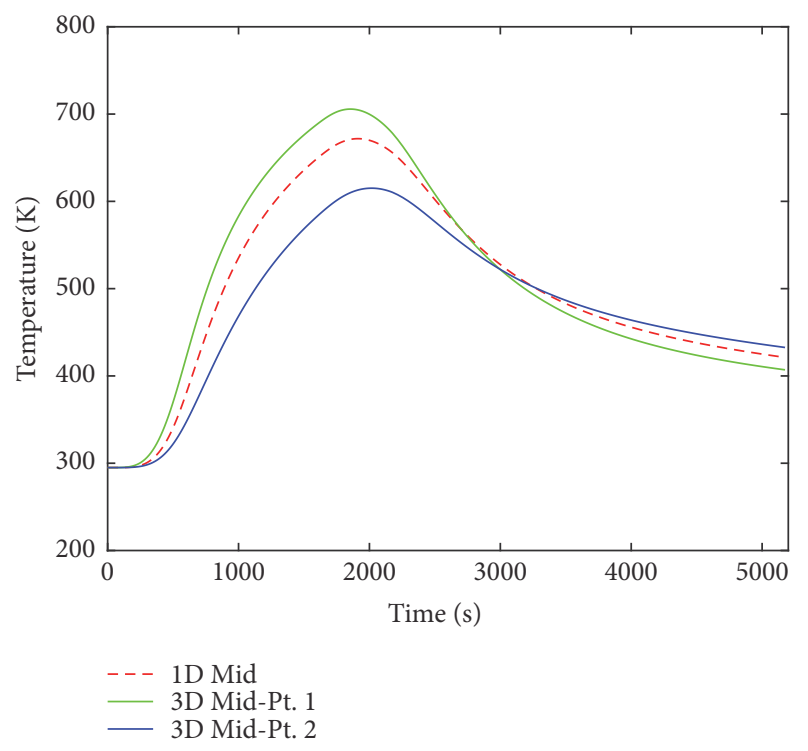

FIgURE 8: Temperature variations at web middle (Mid) for the $1 \mathrm{D}$ and $3 \mathrm{D}$ folded core thermal models.

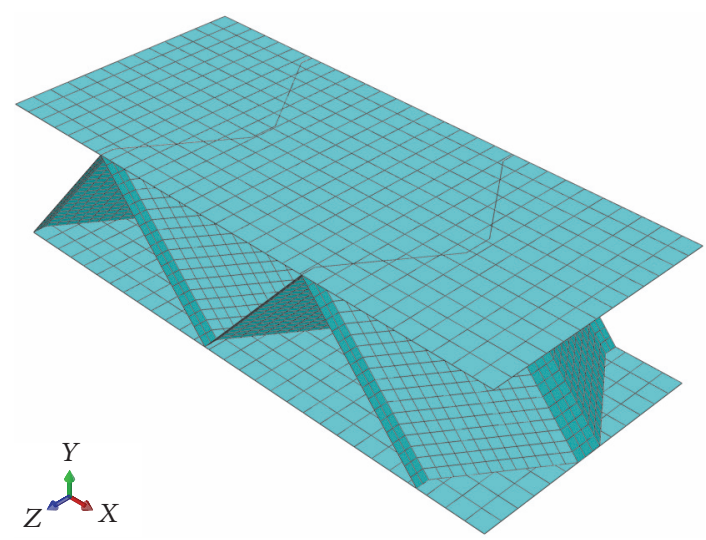

FIGURE 9: Typical mesh for linear static analysis.

The connections between face sheets and the core are accomplished by surface-based tie constraints. Temperatures and aerodynamic pressure loads are applied. Temperature profile data are taken from the $1 \mathrm{D}$ heat transfer analysis described in the previous section at the time when the topface sheet reaches its maximum temperature throughout the whole reentry stage. Then smooth temperature distributions are obtained by fitting a quartic polynomial to the actual temperature data. These polynomials are used to assign temperatures to corresponding linear static models. In this way, we assume that the panel temperatures are uniform throughout their respective lengths and widths, a necessary and limiting consequence of using a 1D thermal model. By considering the temperature variation throughout the panel thickness, this approximation is deemed to be acceptable.

A uniform pressure load of $101325 \mathrm{~Pa}$, which is considered as the maximum pressure that the ITPS may encounter during reentry [3], is applied on the inner surface of the top-face sheet. The model is shown in Figure 10. Symmetric

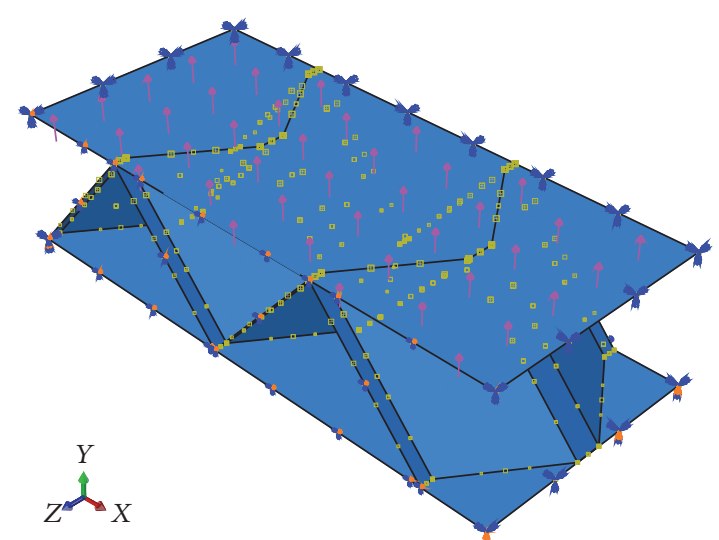

FIgURE 10: Pressure and temperature loads on the panel.

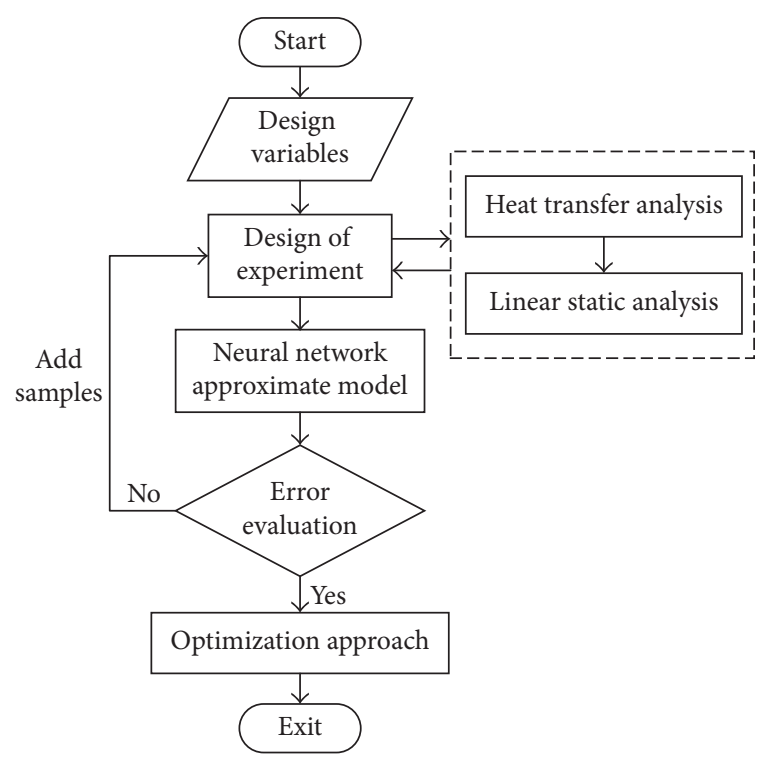

FIGURE 11: Designing process of optimization.

boundary conditions ( $Z$-axis) are applied to the symmetric edges. For the other three edges, which are the actual panel edges, the bottom-face sheet edges were fixed in vertical displacement ( $Y$-axis) and all three rotations, and the top-face sheet edges were fixed in all three rotations while allowing all three displacements to occur. In addition, a fixed $X$ displacement is applied at the intersection point between two actual edges of the bottom-face sheet to eliminate the rigid body modes.

\section{Optimization Study}

5.1. Optimization Approach. A combined optimization approach is adopted as shown in Figure 11. Both of the thermal and structural models are generated parametrically in order to carry out the sensitivity study and optimization procedure efficiently. In order to reduce the computational time, simpler, approximate models were established for both objective function and constraints. This was done using 
radial basis functions (RBF) [30], which are a type of neural network employing a hidden layer of radial units and an output layer of linear units. This neural network is suitable for approximating a wide range of nonlinear spaces.

First, a Latin Hypercube Sampling (LHS) [31] technique was used for the design of experiments (DOE). Variables are normally referred to as factors in a DOE study, while values of variables are known as levels. With the LHS technique, the design space for each factor is uniformly divided, and then these levels are randomly combined to specify sample points defining the design matrix. It provides an efficient method for generating random sample points, which also have a uniform distribution over the entire design space. Then heat transfer and linear static analyses were conducted, respectively, for these samples and corresponding responses obtained.

Afterwards, RBF approximate models were generated based on these data. A set of random points in the complete design space validate its accuracy. These approximate models were continuously updated with additional sample points until necessary accuracy is obtained, which were then used to replace FEM models in the following optimization process.

During optimization, the multi-island genetic algorithm (MIGA) [32] was employed first to locate the approximate global optimal solution. Genetic algorithms (GA) treat complex nonlinear optimizations relatively well. MIGA, which is a further development of GA, divides each population of individuals into several subpopulations called islands, and traditional genetic operations are performed on each island separately. Several individuals are then selected from each island and migrated to different islands periodically. The migration operation maintains the diversity of probable solutions and prevents the premature phenomena. Finally, based on the MIGA solution, sequential quadratic programming was applied to further find the optimum design.

5.2. Sensitivity Study. Sensitivity studies were conducted based on the homogenized 1D transient heat transfer analysis to investigate the contribution of different geometric parameters to the ITPS responses.

Isight [33] is employed to facilitate the conducting of the DOE by Abaqus. Altogether 100 sample points were studied, and then the most influential parameters were obtained through sensitivity analyses. The sensitivity analyses results for maximum bottom-face sheet temperature, areal density of the panel, and maximum top-face sheet deflection are presented using bar graphs in Figures 12-14, blue for positive effect and red for negative effect.

The sensitivity bar graphs plotted in Figure 12 indicate that the folded core height $H$ plays a leading role in the inner temperature control. A larger height means thicker insulation material, which blocks most of the heat flux that flows into the panel. $L$ also has a remarkable negative effect on the bottomface sheet temperature; with the $L$ increasing, the unit cell density decreases, which leads to a longer heat transfer path. The bottom-face sheet acts as a heat sink component, so thickness of bottom-face sheet $t_{\mathrm{BFS}}$ is also an influential parameter. A thicker web means more heat is conducted to the bottom-face sheet, so the web thickness $t$ adversely affects the bottom-face sheet temperature.

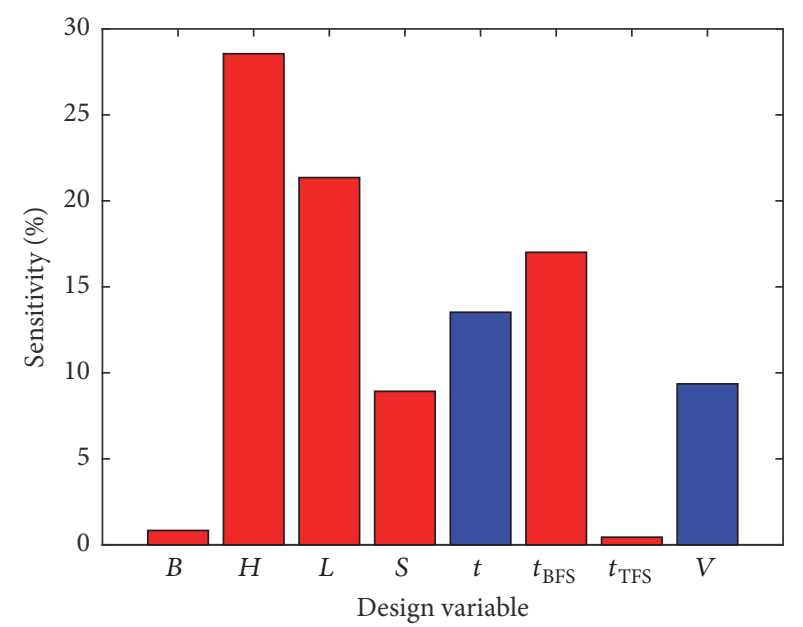

FIGURE 12: Sensitivity indices for the maximum bottom-face sheet temperature.

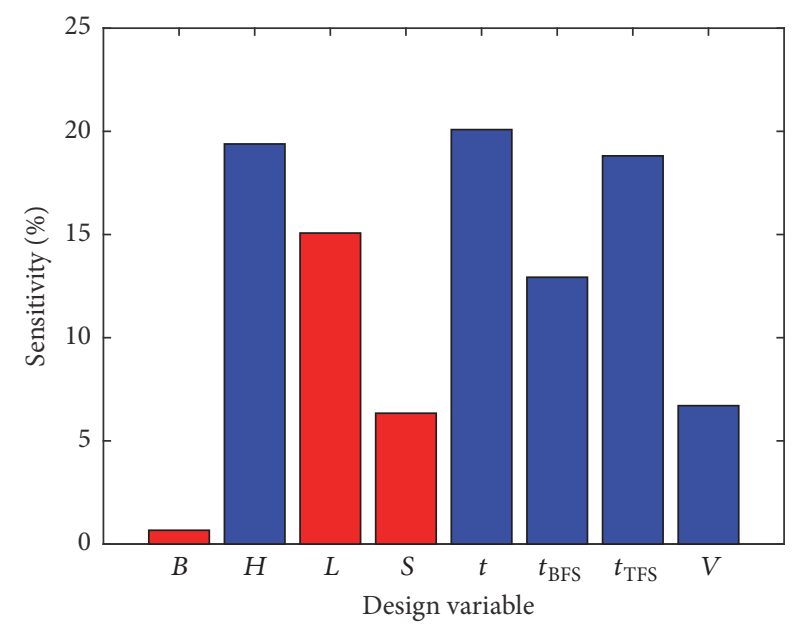

FIGURE 13: Sensitivity indices for the areal density.

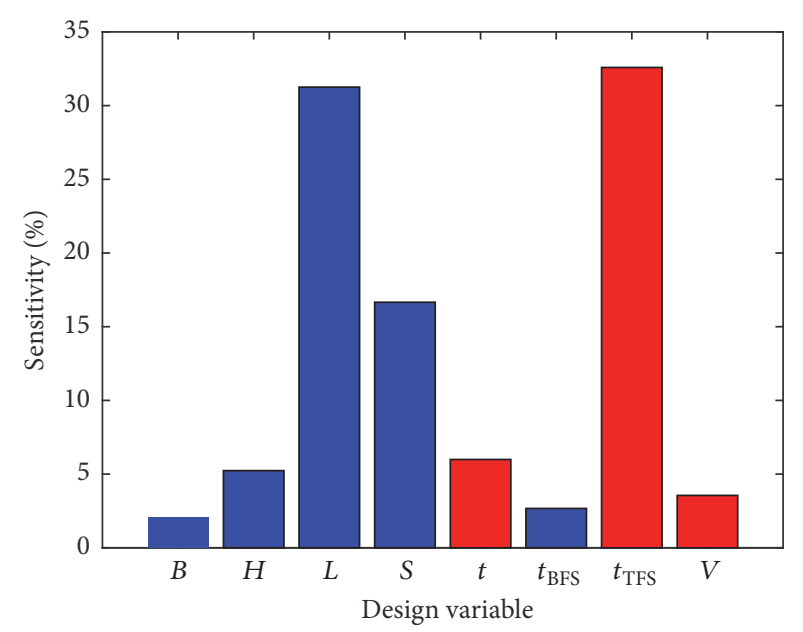

FIGURE 14: Sensitivity indices for the maximum top-face sheet deflection. 
TABLE 1: Ranges of design variables.

\begin{tabular}{lccccccc}
\hline Parameter & $H$ & $L$ & $V$ & $S$ & $t_{\text {TFS }}$ & $t_{\text {BFS }}$ & $t$ \\
\hline Value $(\mathrm{mm})$ & $60-120$ & $50-100$ & $50-100$ & $50-100$ & $1-3$ & $2-6$ & $1-3$ \\
\hline
\end{tabular}

TABLE 2: Evaluation of approximate model.

\begin{tabular}{lcc}
\hline Parameter & RMSE & $R^{2}$ \\
\hline$T_{\text {botmax }}$ & 0.022 & 0.999 \\
Areal density & 0.011 & 0.999 \\
\hline
\end{tabular}

Figure 13 shows the sensitivity indices for the areal density. It is seen that the thickness of the core and face sheets together with the folded core height $H$ contributes most to the areal density. In contrast, a larger $L$ and $S$ mean a larger panel area, which results in a minor areal density.

From Figure 14, the panel dimension and the top-face sheet thickness $t_{\text {TFS }}$ are seen to be relatively important factors for top-face sheet deflection. Due to the fact that the topface sheet temperature is close to the radiation equilibrium temperature, the temperature distribution through the panel thickness has little effect on the top-face sheet deflection. Such considerations explain why the sensitivity indices of the top-face sheet deflection with respect to $H, t, t_{\mathrm{BFS}}$, and $V$ are relatively low, although they greatly affect the maximum bottom temperature, as shown in Figure 12.

5.3. Thermal Optimization. In this section, only the thermal model is taken into consideration. According to our previous sensitivity study, the spacing $B$ has little effect on bottomface sheet temperature, areal density, and top-face sheet deflection. It is fixed here $(B=20 \mathrm{~mm})$ in order to reduce the number of design variables. The ranges of the design variables are the same as those used in the sensitivity study as shown in Table 1.

The mass per unit area of the panel, used as the objective function, is simply given by

$$
\text { areal density }=\rho_{e} \cdot H+\rho_{\mathrm{TFS}} \cdot t_{\mathrm{TFS}}+\rho_{\mathrm{BFS}} \cdot t_{\mathrm{BFS}} .
$$

The maximum bottom-face sheet temperature, which must be below a certain temperature limit, is taken as the constraint.

The optimization problem is succinctly described by

$$
\begin{array}{ll}
\min & \text { areal density, } \\
\text { s.t. } & T_{\text {botmax }} \leq 453 \mathrm{~K} .
\end{array}
$$

First, 300 points were selected in the design space using LHS and then used to construct the approximate model for both objective and constraint functions. Another 50 random points were used to evaluate the accuracy of the approximate model. Details are shown in Table 2, where RMSE stands for root mean square error and $R^{2}$ stands for coefficient of determination. It is shown that the approximations for maximum bottom-face sheet temperature and areal density are of high quality.
Afterwards, the approximate model was used to replace the previous FEM thermal model to carry out the optimization process. The critical parameters of MIGA are as follows: the subpopulation size is 20 , the number of islands is three, the number of generations is 50 , the rates of crossover and mutation are 1.0 and 0.01 , the rate of migration is 0.1 , and the migration interval is five.

Three cases are considered, and the optimal results are shown in Table 3. It is seen that $L$ and $S$ are at their upper bounds to maximize the area of the panel. $V, t$, and $t_{\mathrm{TFS}}$ are at their lower bounds to minimize the proportion of the core web and top-face sheet. The optimal results show the same trends as the sensitivity analysis results. When the ITPS has a less restrictive temperature requirement, $t_{\mathrm{BFS}}$ is at its lower bound, while $H$ increases as the bottom-face sheet temperature limit reduces. As the bottom-face sheet acts as a heat sink component, $t_{\mathrm{BFS}}$ increases to contain extra heat once $H$ reaches its upper bound.

5.4. Thermal-Mechanical Optimization. A large top-face sheet deflection could change the flow around the ITPS, which can lead to a notable increase in aerodynamic heating. On the basis of our previous thermal optimization, a linear static model is now taken into our consideration. The design space and objective function are the same as those used during the thermal optimization, while maximum top-face sheet deflection constraint is imposed as well as the bottomface sheet temperature limits. Linear static analyses show that extremely high stresses occur locally due to the boundary effects, while the stress of sections away from the boundary lies far within the material strength. Hence, stress is not considered as a constraint.

The optimization problem is simply stated as follows:

$$
\begin{array}{ll}
\min & \text { areal density, } \\
\text { s.t. } & T_{\text {botmax }} \leq 453 \mathrm{~K}, \\
& \frac{d_{\mathrm{TFS}}}{D} \leq 0.008,
\end{array}
$$

where $d_{\text {TFS }}$ refers to the maximum top-face sheet deflection and $D$ is the diagonal length of the panel. Here, 400 LHS-obtained points were used first to establish the RBF approximation, whilst 50 random points were used to verify its accuracy. In order to achieve an acceptable error level, 200 additional sample points were sequentially added to the design space. Accuracy evaluation results are shown in Table 4.

Finally, thermal-mechanical optimization was conducted based on this approximate model. The parameter values used in MIGA are the same as those in last section. Optimal results are shown in Table 5 . It is seen that $H, t_{\mathrm{BFS}}$ and $t$ are mainly influenced by the temperature constraint, similarly to the tendency reflected in the thermal optimization. Top-face sheet thickness is no longer at its lower bound and is dominated by the top-face sheet deflection and also varies slightly with the temperature constraint. From cases (1)-(3), $t_{\mathrm{TPS}}$ increases to meet a more challenging deflection constraint, which also means that more heat is conducted into the panel; in order 
TABLE 3: ITPS thermal optimization results.

\begin{tabular}{lcccccccccc}
\hline Case & $\begin{array}{c}T_{\text {botmax }} \\
(\mathrm{K})\end{array}$ & $\begin{array}{c}L \\
(\mathrm{~mm})\end{array}$ & $\begin{array}{c}H \\
(\mathrm{~mm})\end{array}$ & $\begin{array}{c}V \\
(\mathrm{~mm})\end{array}$ & $\begin{array}{c}S \\
(\mathrm{~mm})\end{array}$ & $\begin{array}{c}B \\
(\mathrm{~mm})\end{array}$ & $\begin{array}{c}t_{\mathrm{TFS}} \\
(\mathrm{mm})\end{array}$ & $\begin{array}{c}t_{\mathrm{BFS}} \\
(\mathrm{mm})\end{array}$ & $\begin{array}{c}t \\
(\mathrm{~mm})\end{array}$ & $\begin{array}{c}M \\
\left(\mathrm{~kg} / \mathrm{m}^{2}\right)\end{array}$ \\
\hline$(1)$ & $423 \mathrm{~K}$ & 100.00 & 120.00 & 50.00 & 100.00 & 20.00 & 1.00 & 2.80 & 1.00 & 28.88 \\
$(2)$ & $453 \mathrm{~K}$ & 100.00 & 115.19 & 50.00 & 100.00 & 20.00 & 1.00 & 2.00 & 1.00 & 26.11 \\
$(3)$ & $473 \mathrm{~K}$ & 100.00 & 102.31 & 50.00 & 100.00 & 20.00 & 1.00 & 2.00 & 1.00 & 25.10 \\
\hline
\end{tabular}

TABLE 4: Evaluation of approximate model.

\begin{tabular}{lcc}
\hline Parameter & RMSE & $R^{2}$ \\
\hline$T_{\text {botmax }}$ & 0.002 & 0.999 \\
$d_{\text {TFS }} / D$ & 0.026 & 0.985 \\
Areal density & 0.002 & 0.999 \\
\hline
\end{tabular}

to maintain the bottom-face sheet temperature, $t_{\mathrm{BFS}}$ increases along with $t_{\mathrm{TFS}}$.

The optimized variables for cases (2) and (4) were subsequently input into the finite element analyses. A comparison of the RBF predictions and FEM results is shown in Table 6. The relative error between the RBF and FEM values is less than $5 \%$, which indicates that the approximate model has fairly good accuracy.

Figure 15 illustrates the displacement contour of the ITPS panel in the $Y$ direction for case (2). It is seen that the local effects of the pressure loading only appear on the top-face sheet and the maximum deflection occurs at the middle of the top-face sheet.

In the above optimization process, temperature and displacement are taken as constraints, while buckling, which is also likely to cause catastrophic failure, is not considered. Therefore, additional buckling analyses are conducted for case (2) at three different times, that is, times (Time 1, Time 2 , and Time 3 ) when top-face sheet, web middle, and bottomface sheet reach their respective maximum temperature. The same model as the linear static analysis is used in the buckling analysis. The minimum positive eigenvalues $\lambda$ are listed in Table 7 and the corresponding buckling models are shown in Figure 16. It is seen that buckling would probably not occur for the current design of case (2).

From the temperature variations in Figures 6-8, the times when the top-face sheet and web middle reach their maximum temperature are quite close, which leads to a similar buckling mode as shown in Figures 16(a) and 16(b). When the bottom-face sheet temperature reaches its maximum, the temperature distribution through the whole panel thickness is significantly changed compared with the other two. Hence, the web buckles in a different position at Time 3 as shown in Figure 16(c).

\section{Conclusions}

A novel thermal-mechanical optimization procedure has been developed for the folded core-based integrated thermal protection system (ITPS) concept. In addition, an improved analytical rule of mixtures approach for calculating thermal conductivity considering the inclined shape of the folded core

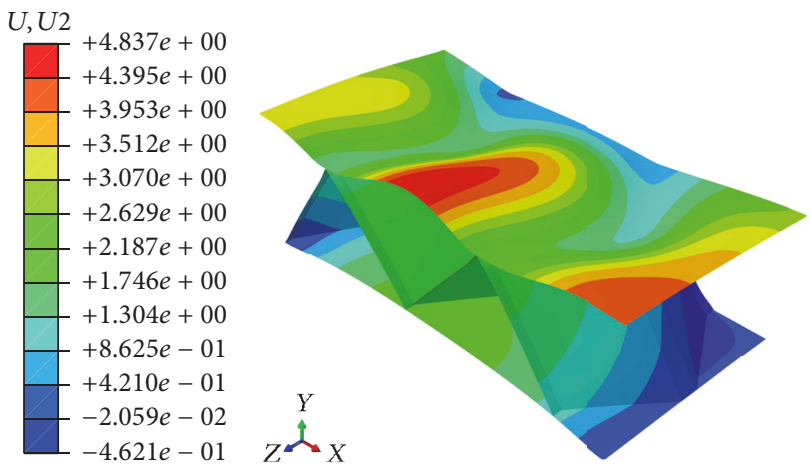

FIGURE 15: The $Y$-direction displacement contour of the ITPS panel.

has been presented and a thermal model that homogenizes variations through the structure was developed to reduce the computational cost associated with a $3 \mathrm{D}$ structure. Then sensitivity analyses as well as optimization studies were performed to identify key variables of influence. Key conclusions are considered below.

The comparative thermal analyses show that the $1 \mathrm{D}$ model has a relatively high accuracy in comparison with $3 \mathrm{D}$ models for heat transfer analysis. This approach reduces the computational time by nearly 70 percent, while maintaining sufficiently accurate prediction of temperature distribution. For current material combinations, the bottom-face sheet temperature decreases significantly with an increasing folded core height, saw-tooth lines pitch, and bottom-face sheet thickness. The ideal web thickness is found, not surprisingly, to be as thin as possible in order to reduce the mass and the amount of heat entering the panel. The spacing between the saw-tooth lines has little effect on the responses considered in this paper. The radial basis function approximations are shown to be of high quality and can be used instead of more expensive FEM models to perform optimization studies.

In the current study, only pressure load and thermal load have been considered; however, the ITPS structure is subjected to various kinds of loads during reentry. Buckling constraints and the influence of the folded core topology should be considered in future work.

\section{Appendix}

\section{Derivation of Homogenized Properties of M-Pattern Folded Core}

Consider a typical M-pattern folded core unit cell as shown in Figure 17(a). It can be folded continuously from a flat sheet consisting of a repetitive combination of parallelogram and 
TABLE 5: ITPS thermal-mechanical optimization results.

\begin{tabular}{|c|c|c|c|c|c|c|c|c|c|c|c|}
\hline Case & $\begin{array}{c}T_{\text {botmax }} \\
(\mathrm{K})\end{array}$ & $d_{\mathrm{TFS}} / D$ & $\begin{array}{c}L \\
(\mathrm{~mm})\end{array}$ & $\begin{array}{c}H \\
(\mathrm{~mm})\end{array}$ & $\begin{array}{c}V \\
(\mathrm{~mm})\end{array}$ & $\begin{array}{c}S \\
(\mathrm{~mm})\end{array}$ & $\begin{array}{c}B \\
(\mathrm{~mm}) \\
\end{array}$ & $\begin{array}{c}t_{\mathrm{TFS}} \\
(\mathrm{mm})\end{array}$ & $\begin{array}{c}t_{\mathrm{BFS}} \\
(\mathrm{mm})\end{array}$ & $\begin{array}{c}t \\
(\mathrm{~mm})\end{array}$ & $\begin{array}{c}M \\
\left(\mathrm{~kg} / \mathrm{m}^{2}\right)\end{array}$ \\
\hline (1) & $423 \mathrm{~K}$ & 0.006 & 89.90 & 109.30 & 59.56 & 86.32 & 20.00 & 1.73 & 3.93 & 1.00 & 38.08 \\
\hline (2) & $423 \mathrm{~K}$ & 0.008 & 91.83 & 109.24 & 58.40 & 86.33 & 20.00 & 1.57 & 3.82 & 1.00 & 36.29 \\
\hline (3) & $423 \mathrm{~K}$ & 0.01 & 92.24 & 109.38 & 57.04 & 86.30 & 20.00 & 1.44 & 3.76 & 1.00 & 35.07 \\
\hline (4) & $453 \mathrm{~K}$ & 0.008 & 87.54 & 101.30 & 58.73 & 86.75 & 20.00 & 1.47 & 3.16 & 1.00 & 33.17 \\
\hline (5) & $473 \mathrm{~K}$ & 0.008 & 84.72 & 96.72 & 58.04 & 86.00 & 20.00 & 1.44 & 2.84 & 1.00 & 31.69 \\
\hline
\end{tabular}

TABLE 6: Comparison of predicted results with FEM results.

\begin{tabular}{lccc}
\hline Case & $T_{\text {botmax }}(\mathrm{K})$ & $d_{\mathrm{TFS}} / D$ & $M\left(\mathrm{~kg} / \mathrm{m}^{2}\right)$ \\
\hline$(2)$ & & & 0.008 \\
RBF & 423 & 0.00804 & 36.29 \\
FEM & 423.36 & 0.498 & 36.32 \\
Error (\%) & 0.085 & & 0.083 \\
$(3)$ & & 0.01 & 35.07 \\
RBF & 423 & 0.00962 & 35.05 \\
FEM & 423.49 & 3.950 & 0.057 \\
Error (\%) & 0.116 & & \\
\hline
\end{tabular}

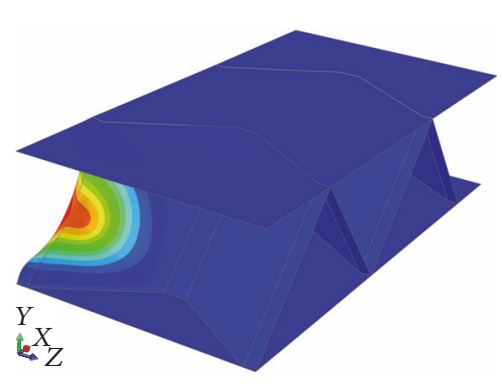

(a)

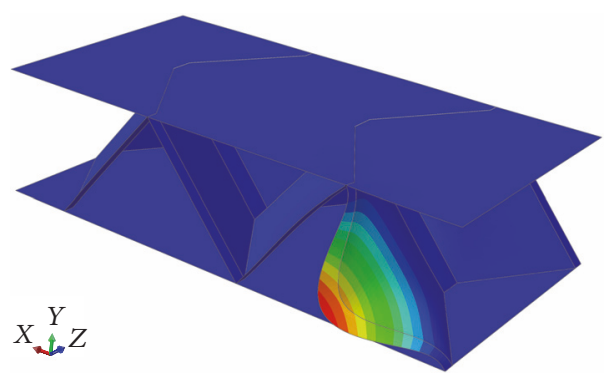

(b)

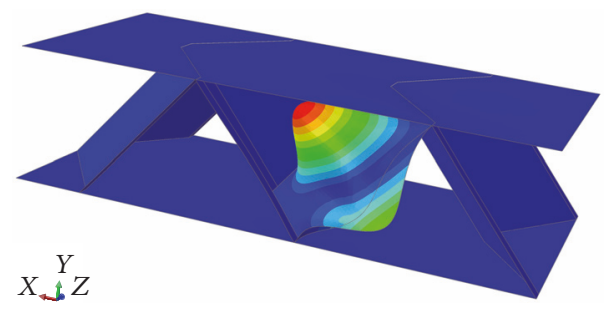

(c)

FIGURE 16: Buckling modes of the ITPS panel. (a) Web buckling when TFS reaches maximum temperature. (b) Web buckling when web middle reaches maximum temperature. (c) Web buckling when BFS reaches maximum temperature.

rectangular plates as shown in Figure 17(b). The parameters of the flat sheet can be derived from those of the corresponding folded core as $[13,21]$

$$
\begin{aligned}
& L_{0}=\sqrt{H^{2}+L^{2}}, \\
& V_{0}=\frac{L V}{\sqrt{H^{2}+L^{2}}}, \\
& S_{0}=\sqrt{S^{2}+\frac{H^{2} V^{2}}{H^{2}+L^{2}}} .
\end{aligned}
$$

The included angle $\varphi$, which could vary in the range of $0^{\circ}$ to $90^{\circ}$, is related to independent parameters by

$$
\tan \varphi=\frac{S_{0}}{V_{0}}=\frac{\sqrt{S^{2}\left(H^{2}+L^{2}\right)+H^{2} V^{2}}}{L V} .
$$

As $\sin \varphi$ is more frequently used in the following derivations, the relation between the included angle and independent parameters is rearranged as

$$
\sin \varphi=\frac{\tan \varphi}{\sqrt{1+(\tan \varphi)^{2}}}=\sqrt{\frac{S^{2}\left(H^{2}+L^{2}\right)+H^{2} V^{2}}{\left(H^{2}+L^{2}\right)\left(S^{2}+V^{2}\right)}} .
$$




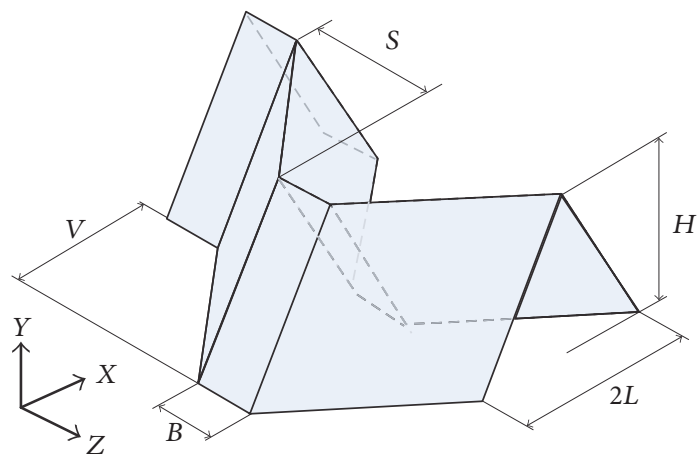

(a)

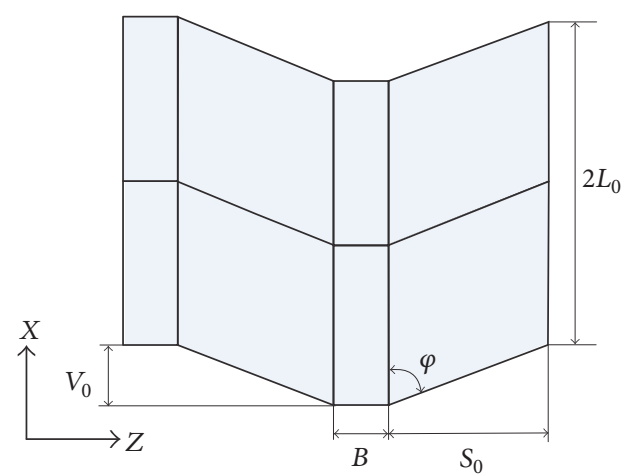

(b)

FIGURE 17: Geometric parameters of (a) an M-pattern folded core and (b) the corresponding crease pattern.

TABLE 7: Minimum positive eigenvalues of the ITPS panel at three different times.

\begin{tabular}{lc}
\hline Parameter & $\lambda$ \\
\hline Time 1 & 1.1319 \\
Time 2 & 2.2520 \\
Time 3 & 1.1679 \\
\hline
\end{tabular}

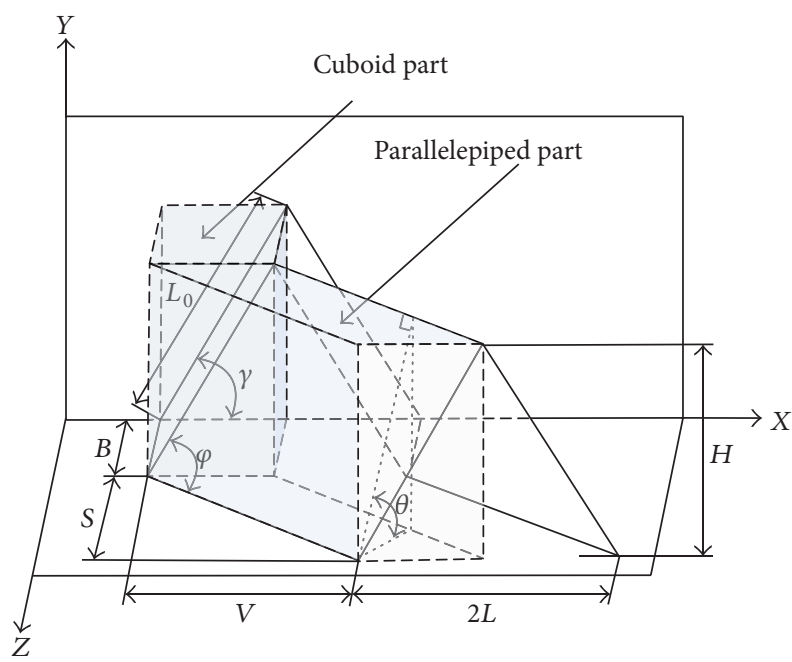

FIGURE 18: Illustration of the half unit cell and inclined angles.

The effective thermal conductivity of the folded core along the core thickness direction ( $Y$-direction) can be derived by analysing heat conduction through the half unit cell shown in Figure 18. By considering the inclination of the webs, thermal conductivity along the thickness direction could not be simply homogenized using the general rule of mixtures. Amendments are achieved by introducing inclined angles $\theta$ and $\gamma$ for the parallelepiped and cuboid part, respectively. For simplicity, both panels are assumed to be free of process-induced geometrical imperfections and have uniform web thickness.
For the parallelepiped part (see Figure 19(a)), that is, $S$ part, the effective thermal conductivity $k_{e}{ }^{S}$ is given by

$$
k_{e}{ }^{S} \approx k_{w} \cdot\left(V_{w}{ }^{S} \cdot \sin ^{2} \theta \cdot \sin \varphi\right)+k_{s} \cdot V_{s}^{S},
$$

where $V_{w}^{S}$ and $V_{s}^{S}$ are the volume fraction of the web and SAFFIL:

$$
\begin{aligned}
V_{w}{ }^{S} & =\frac{\sqrt{S^{2}+V^{2}} \cdot\left(L_{0} \sin \varphi\right) \cdot t}{L \cdot H \cdot S}, \\
V_{s}^{S} & =1-V_{w}{ }^{S} .
\end{aligned}
$$

Similarly, for the cuboid part (see Figure 19(b)), that is, $B$ part,

$$
k_{e}{ }^{B} \approx k_{w} \cdot\left(V_{w}{ }^{B} \cdot \sin ^{2} \gamma\right)+k_{s} \cdot V_{s}^{B},
$$

where $V_{w}{ }^{B}$ and $V_{s}{ }^{B}$ are the volume fraction of the web and SAFFIL:

$$
\begin{aligned}
V_{w}{ }^{B} & =\frac{B \cdot L_{0} \cdot t}{L \cdot H \cdot B}, \\
V_{s}{ }^{B} & =1-V_{w}{ }^{B} .
\end{aligned}
$$

Once the effective thermal conductivity for each part is obtained, the general rule of mixtures is used. The homogenized thermal conductivity of the proposed folded core can then be expressed as

$$
k_{e}=k_{e}{ }^{S} \cdot V^{S}+k_{e}{ }^{B} \cdot V^{B},
$$

where $V^{S}$ and $V^{B}$ refer to the volume fraction of the parallelepiped and cuboid part, respectively.

$$
\begin{aligned}
V^{S} & =\frac{S}{S+B}, \\
V^{B} & =1-V^{S} .
\end{aligned}
$$

By invoking (A.4) and (A.6), (A.8) can be rewritten as

$$
\begin{aligned}
k_{e}= & {\left[k_{w} \cdot\left(V_{w}{ }^{S} \cdot \sin ^{2} \theta \cdot \sin \varphi\right)+k_{s} \cdot V_{s}{ }^{S}\right] \cdot V^{S} } \\
& +\left[k_{w} \cdot\left(V_{w}{ }^{B} \cdot \sin ^{2} \gamma\right)+k_{s} \cdot V_{s}{ }^{B}\right] \cdot V^{B} .
\end{aligned}
$$




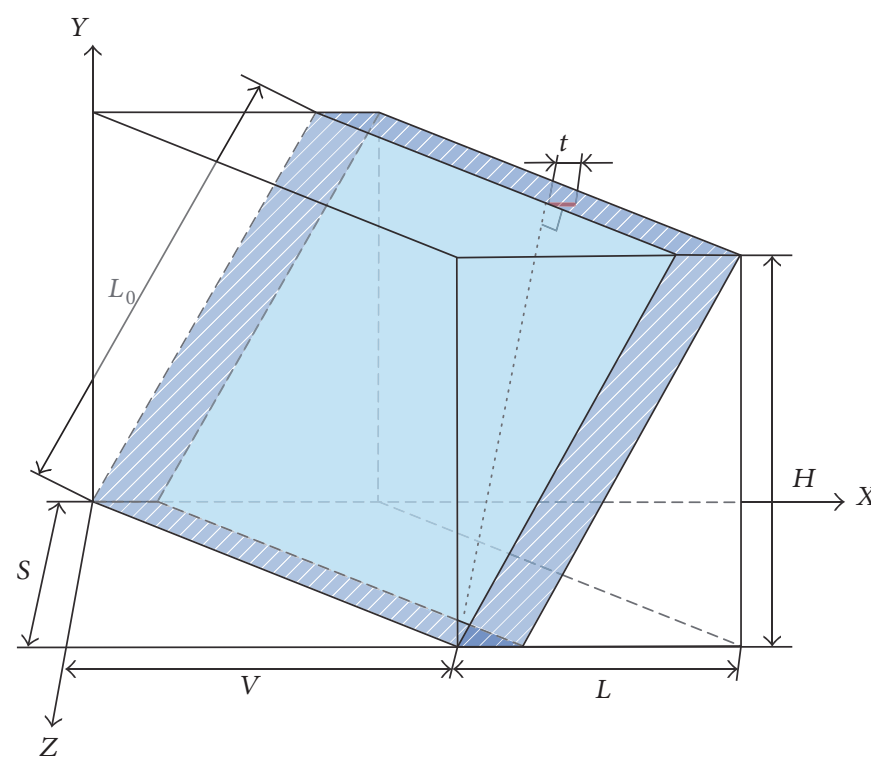

(a)

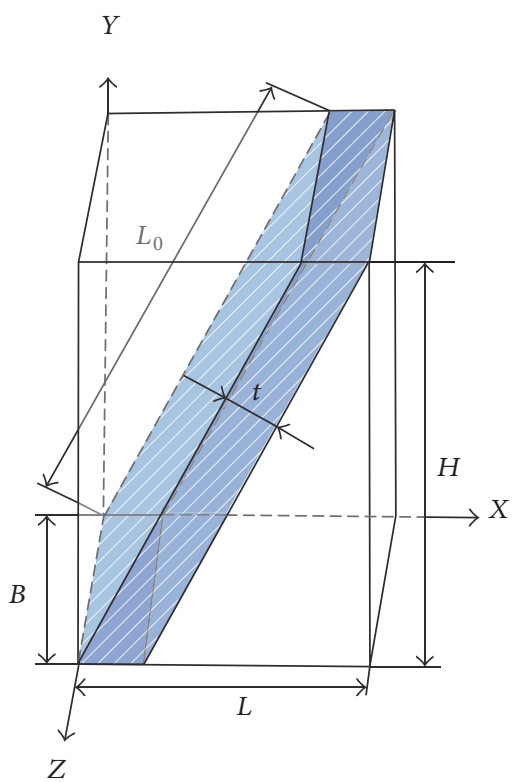

(b)

FIGURE 19: Schematics of (a) parallelepiped and (b) cuboid part when web thickness is considered.

The effective density and specific heat of the homogenized folded core is readily calculated by imposing the general rule of mixtures:

$$
\begin{aligned}
& \rho_{e}=\rho_{w} \cdot V_{w}+\rho_{s} \cdot V_{s} \\
& c_{e}=\frac{1}{\rho_{e}}\left(c_{w} \cdot \rho_{w} \cdot V_{w}+c_{s} \cdot \rho_{s} \cdot V_{s}\right),
\end{aligned}
$$

where $V_{w}$ and $V_{s}$ are the volume fraction of the web and SAFFIL for the folded core unit cell:

$$
\begin{aligned}
& V_{w}=\frac{\sqrt{S^{2}+V^{2}} \cdot\left(L_{0} \sin \varphi\right) \cdot t+B \cdot L_{0} \cdot t}{L \cdot H \cdot S+L \cdot H \cdot B} \\
& V_{s}=1-V_{w} .
\end{aligned}
$$

\section{Conflicts of Interest}

The authors declare that they have no conflicts of interest.

\section{Acknowledgments}

This work was supported by Funding of Jiangsu Innovation Program for Graduate Education [Grant no. CXLX13_163], the Fundamental Research Funds for the Central Universities [Grant no. NZ2016101], and a project funded by the Priority Academic Program Development of Jiangsu Higher Education Institutions (PAPD). Chen Zhou would also like to thank China Scholarship Council (CSC) for the funding of his research work through University of Bristol.

\section{References}

[1] D. E. Glass, "Ceramic matrix composite (CMC) thermal protection systems (TPS) and hot structures for hypersonic vehicles," in Proceedings of the 15th AIAA International Space Planes and Hypersonic Systems and Technologies Conference, May 2008.

[2] J. F. Rakow and A. M. Waas, "Response of actively cooled metal foam sandwich panels exposed to thermal loading," AIAA Journal, vol. 45, no. 2, pp. 329-336, 2007.

[3] S. K. Bapanapalli, O. M. Martinez, C. Gogu, B. V. Sankar, R. T. Haftka, and M. L. Blosser, "Analysis and design of corrugated-core sandwich panels for thermal protection systems of space vehicles," in Proceedings of the 47th AIAA/ASME/ASCE/AHS/ASC Structures, Structural Dynamics and Materials Conference, pp. 4197-4214, May 2006.

[4] S. Venkataraman, R. T. Haftka, B. V. Sankar, H. Zhu, and M. L. Blosser, "Optimal functionally graded metallic foam thermal insulation," AIAA Journal, vol. 42, no. 11, pp. 2355-2363, 2004.

[5] H. Zhu, B. V. Sankar, R. T. Haftka, and M. Blosser, "Evaluation of integrated sandwich TPS design with metal foam core for launch vehicles," in Proceedings of the 46th AIAA/ASME/ASCE/AHS/ASC Structures, Structural Dynamics and Materials Conference, pp. 4763-4774, April 2005.

[6] A. Sharma, B. V. Sankar, and R. T. Haftka, "Multi-fidelity analysis of corrugated-core sandwich panels for integrated thermal protection systems," in Proceedings of the 50th AIAA/ASME/ASCE/AHS/ASC Structures, Structural Dynamics and Materials Conference, May 2009.

[7] G. Xie, Q. Wang, B. Sunden, and W. Zhang, "Thermomechanical optimization of lightweight thermal protection system under aerodynamic heating," Applied Thermal Engineering, vol. 59, no. 1-2, pp. 425-434, 2013.

[8] F. Jiang, W. Yu, Z. Ye, R. Kerans, and M. Y. Chen, "Analysis of reusable integrated thermal protection panel elements with various insulating core options," in Proceedings of the 55th AIAA/ASMe/ASCE/AHS/SC Structures, Structural Dynamics, and Materials Conference - SciTech Forum and Exposition 2014, January 2014.

[9] K. Wei, R. He, X. Cheng, R. Zhang, Y. Pei, and D. Fang, "A lightweight, high compression strength ultra high temperature 
ceramic corrugated panel with potential for thermal protection system applications," Materials and Design, vol. 66, pp. 552-556, 2015.

[10] T. Lu, D. He, C. Chen, C. Zhao, D. Fang, and X. Wang, "The Multi-functionality of Ultra-light Porous Metals and Their Applications. Advances in Mechanics," in Advances in Mechanics, pp. 517-535, 2007.

[11] G. Xie, W. Qi, W. Zhang, B. Sunden, and G. Lorenzini, "Optimization Design and Analysis of Multilayer Lightweight Thermal Protection Structures Under Aerodynamic Heating Conditions," Journal of Thermal Science and Engineering Applications, vol. 5, no. 1, p. 011011, 2013.

[12] S. Fischer, K. Drechsler, S. Kilchert, and A. Johnson, "Mechanical tests for foldcore base material properties," Composites Part A: Applied Science and Manufacturing, vol. 40, no. 12, pp. 19411952, 2009.

[13] Z. Wang, V. I. Khaliulin, and E. Skripkin, "Geometry design method of folded structure," Nanjing Hangkong Hangtian Daxue Xuebao/Journal of Nanjing University of Aeronautics and Astronautics, vol. 34, no. 1, pp. 6-11, 2002.

[14] S. Heimbs, P. Middendorf, C. Hampf, F. H Lhnel, and K. Wolf, "Aircraft sandwich structures with folded core under impact load," in Proceedings of the Proc of the 8th International Conference on Sandwich Structures, ICSS8, Porto, Portugal, 2008.

[15] Z.-J. Wang and Q.-H. Xu, "Experimental research on soundproof characteristic for the sandwich plates with folded core," Zhendong Gongcheng Xuebao/Journal of Vibration Engineering, vol. 19, no. 1, pp. 65-69, 2006.

[16] S. Heimbs, P. Middendorf, S. Kilchert, A. F. Johnson, and M. Maier, "Experimental and numerical analysis of composite folded sandwich core structures under compression," Applied Composite Materials, vol. 14, no. 5-6, pp. 363-377, 2007.

[17] S. Heimbs, J. Cichosz, M. Klaus, S. Kilchert, and A. F. Johnson, "Sandwich structures with textile-reinforced composite foldcores under impact loads," Composite Structures, vol. 92, no. 6, pp. 1485-1497, 2010.

[18] K. Sab and A. Lebée, "Transverse shear stiffness of a chevron folded core used in sandwich construction," International Journal of Solids and Structures, vol. 47, no. 18-19, pp. 2620-2629, 2010.

[19] A. Lebée and K. Sab, "Homogenization of thick periodic plates: Application of the Bending-Gradient plate theory to a folded core sandwich panel," International Journal of Solids and Structures, vol. 49, no. 19-20, pp. 2778-2792, 2012.

[20] M. Klaus, H.-G. Reimerdes, and N. K. Gupta, "Experimental and numerical investigations of residual strength after impact of sandwich panels," International Journal of Impact Engineering, vol. 44, pp. 50-58, 2012.

[21] V. Khaliulin and I. Dvoyeglazov, "On Technological Problems of Fabrication of Relief Designs by Isometric Transformations of Thin Sheet," Transactions of Nanjing University of Aeronautics and Astronautics, vol. 18, pp. 11-18, 2001.

[22] C. C. Poteet, H. Abu-Khajeel, and S.-Y. Hsu, "Preliminary thermal-mechanical sizing of a metallic thermal protection system," Journal of Spacecraft and Rockets, vol. 41, no. 2, pp. 173182, 2004.

[23] S. D. Williams and D. M. Curry, "Thermal protection materials: Thermophysical property data," Medium: X; Size, p. 204, 1992.

[24] D. G. Ahn, K. W. Byun, and M. C. Kang, "Thermal characteristics in the cutting of Inconel 718 superalloy using CW Nd:YAG laser," Journal of Materials Science and Technology, vol. 26, no. 4, pp. 362-366, 2010.

[25] M. L. Blosser, Advanced Metallic Thermal Protection Systems for Resuable Launch Vehicles [Ph.D. thesis], School of Engineering and Applie Science, 2000.

[26] J. R. Miller and P. M. Weaver, "Temperature distribution in a composite box structure subject to transient heat fluxes," Journal of Thermophysics and Heat Transfer, vol. 17, no. 2, pp. 269-277, 2003.

[27] J. R. Miller and P. M. Weaver, "Temperature profiles in composite plates subject to time-dependent complex boundary conditions," Composite Structures, vol. 59, no. 2, pp. 267-278, 2003.

[28] Dassault Systemes Simulia Corp. Abaqus 6.14 Scripting User's Guide. Dassault Systemes Simulia Corp. 2014.

[29] D. E. Myers, C. J. Martin, and M. L. Blosser, "Parametric weight comparison of advanced metallic, ceramic tile, and ceramic blanket thermal protection systems," NASA Technical Memorandum, no. 210289, 2000.

[30] Z. Yun, Z. Quan, S. Caixin, L. Shaolan, L. Yuming, and S. Yang, "RBF neural network and ANFIS-based short-term load forecasting approach in real-time price environment," IEEE Transactions on Power Systems, vol. 23, no. 3, pp. 853-858, 2008.

[31] M. D. Mckay, R. J. Beckman, and W. J. Conover, "A comparison of three methods for selecting values of input variables in the analysis of output from a computer code," Technometrics, vol. 42 , no. 1, pp. 55-61, 2000.

[32] X. Meng, J. Ni, and Y. Zhu, "Research of active vibration control optimal disposition based on MIGA and NSGA-II," in Proceedings of the 2010 6th International Conference on Natural Computation, ICNC'10, pp. 4209-4214, August 2010.

[33] Dassault Systemes Simulia Corp. Isight 5.7 User's Guide. Dassault Systemes Simulia Corp. 2012. 


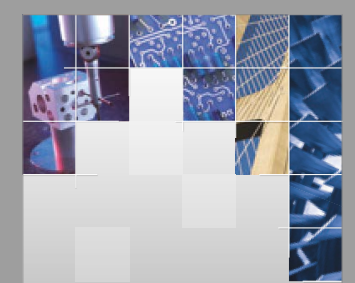

\section{Enfincering}
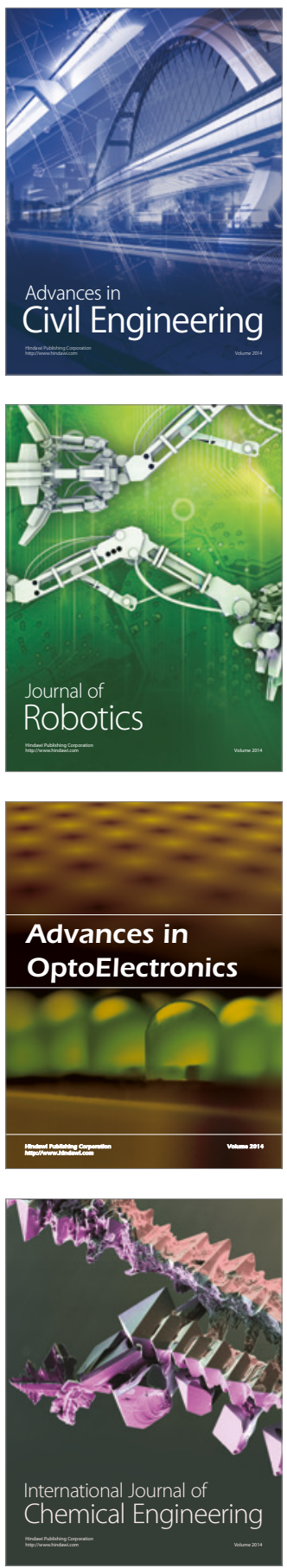

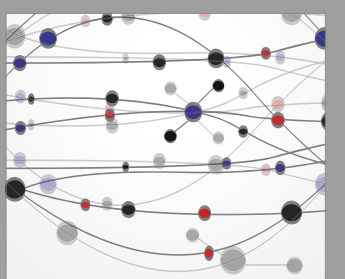

The Scientific World Journal

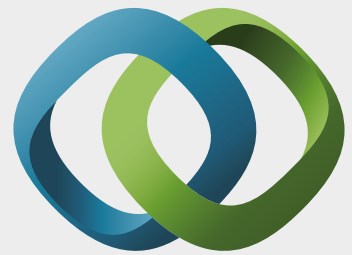

\section{Hindawi}

Submit your manuscripts at

https://www.hindawi.com
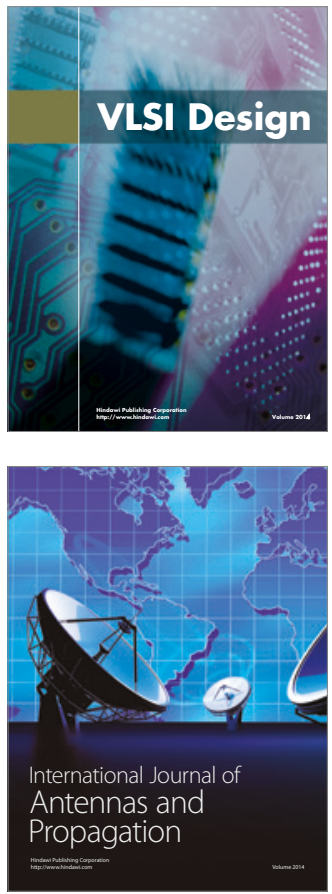

\section{Rotating}

Machinery
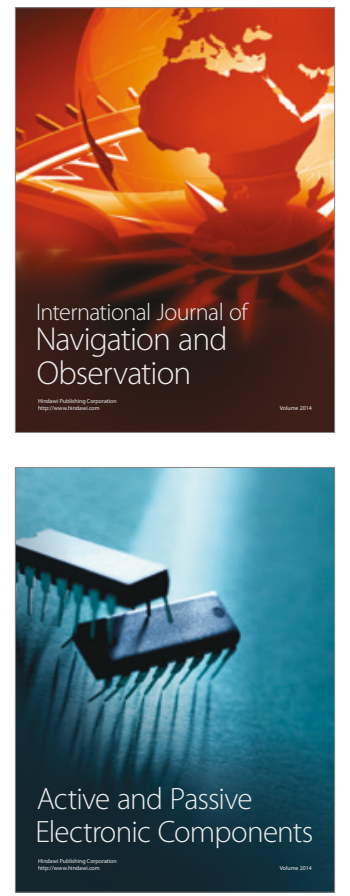
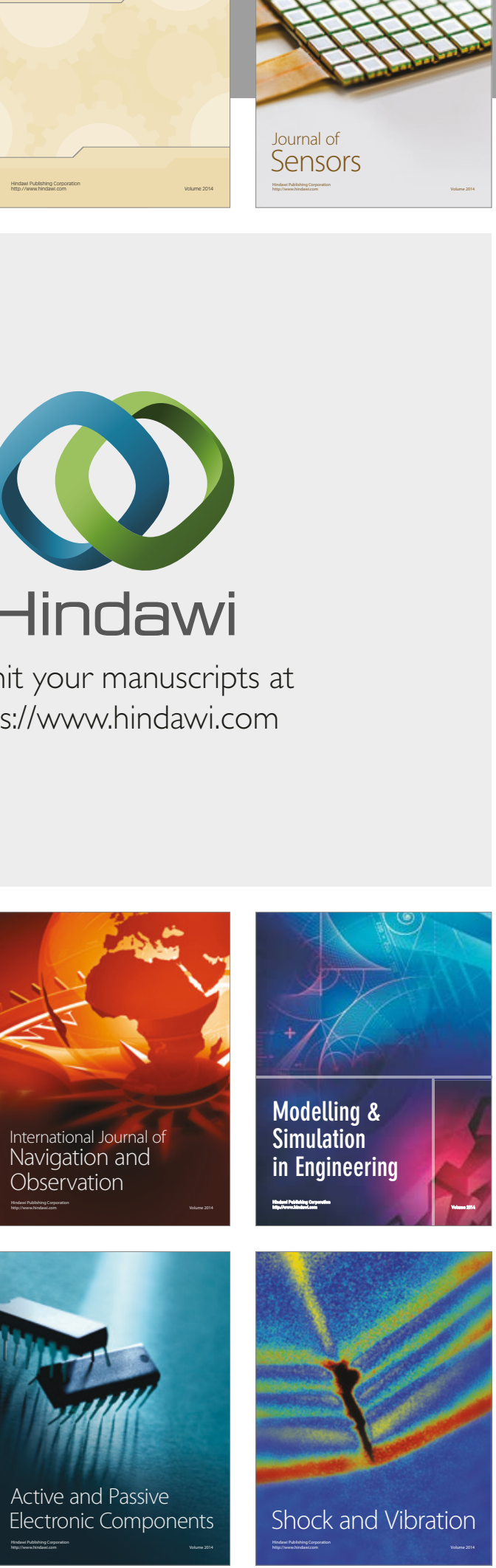
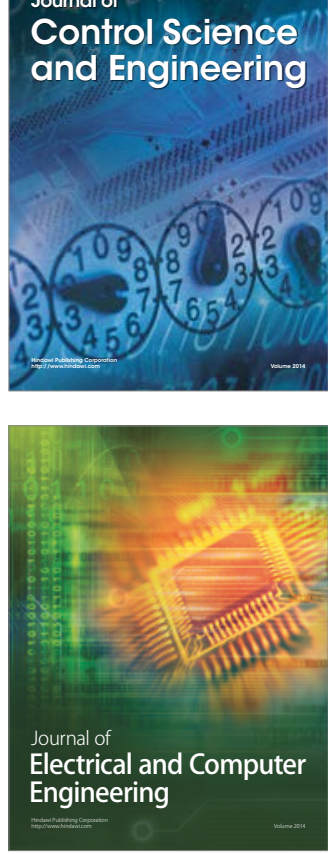

Distributed

Journal of

Control Science

and Engineering
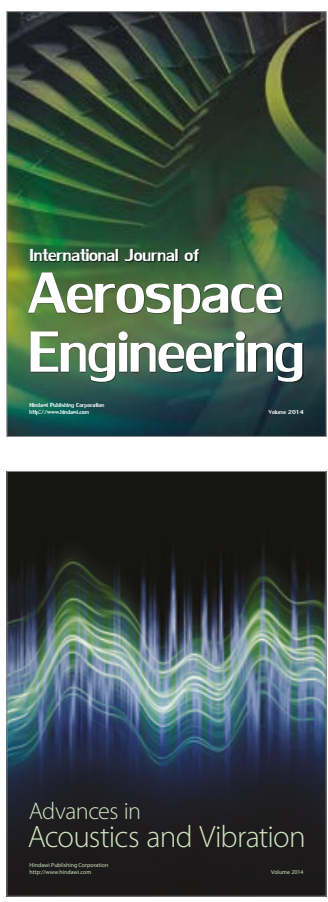

Sensor Networks 